\title{
UPAYA MENINGKATKAN HASIL BELAJAR MATEMATIKA DENGAN MENGGUNAKAN MODEL EXPLICIT INSTRUCTION DAN COURSE REVIEW HORAY BERBANTU MEDIA MANIPULATIF PADA PESERTA DIDIK KELAS V B DI SDN-3 LANGKAI PALANGKARAYA TAHUN PELAJARAN 2017/2018
}

\section{Oleh: Desi Dwi Mariana Putri* \& Ichyatul Afrom, M.Pd}

\begin{abstract}
Abstrak
Penelitian ini bertujuan untuk mendeskripsikan aktivitas belajar Matematika dengan menggunakan model Model Explicit Instruction dan Course Review Horay berbantu media manipulative serta meningkatan hasil belajar Matematika dengan menggunakan model model Explicit Instruction dan Course Review Horay berbantu media manipulatif. Jenis penelitian ini adalah penelitian tindakan kelas (PTK). Subyek penelitian ini adalah peserta didik kelas V B berjumlah 27 peserta didik, terdiri dari 15 laki-laki dan 12 perempuan. Teknik pengumpulan data dalam penelitian ini menggunakan tes dan observasi. Analisis data menggunakan analisis kualitatif dan kuantitatif. Hasil Penelitian menunjukkan bahwa aktivitas belajar peserta didik dengan menggunakan model Explicit Instruction dan Course Review Horay berbantu media manipulatif pada peserta didik menjadi meningkat, nilai ratarata siklus I adalah 2,87 dengan kriteria kurang baik dan siklus II nilai rata-rata 3,32 dengan kriteria baik. Selain itu, ada peningkatan hasil belajar Matematika dengan menggunakan model Explicit Instruction dan Course Review Horay berbantu media manipulatif pada peserta didik kelas. Nilai rata-rata pre-test yaitu 44 dengan ketuntasan klasikal 25\%, siklus I nilai rata-rata 63 dengan ketuntasan klasikal $51,85 \%$, dan pada siklus II nilai rata-rata 79 dengan ketuntasan klasikal 92,59\%.
\end{abstract}

Kata Kunci: Hasil Belajar, Matematika, Model Explicit Instruction, Model Course Review Horay, Media Manipulatif.

\begin{abstract}
This study aims to describe the learning activities of Mathematics by using the Explicit Instruction Model and Course Review Horay model assisted by manipulative media and improving Mathematics learning outcomes using the Explicit Instruction model and Course Review Horay with the help of the manipulative press. This type of research is classroom action research (CAR). The subjects of this study were 27 students of class V B, consisting of 15 men and 12 women. Data collection techniques in this study used tests and observations. Data analysis used qualitative and quantitative analysis. The results showed that the learning activities of students using the Explicit Instruction and Course Review Horay models assisted manipulative media in students increased, the average value
\end{abstract}


of the first cycle was 2.87 with poor criteria and the second cycle the average cost was 3.32 with suitable measures. Also, there is an increase in Mathematics learning outcomes using the Explicit Instruction model and the Course Review Horay assisted by manipulative media in class students. The average pre-test value is 44 with classical completeness of $25 \%$, the cycle I average cost 63 with artistic integrity $51.85 \%$, and in cycle II the average cost is 79 with artistic integrity $92.59 \%$.

Keywords: Learning Outcomes, Mathematics, Explicit Instruction Model, Course Review Horay Model, Manipulative Media.

\section{PENDAHULUAN}

Pendidikan adalah hal yang sangat mendasar dalam pembentukan kualitas sumber daya manusia untuk menanamkan ilmu pengetahuan dan pembentukan kepribadian peserta didik sesuai karakteristik dan tingkat perkembangan dirinya, sehingga menghasilkan perubahan-perubahan yang positif pada diri peserta didik. Oleh karena itu, untuk menciptakan sumber daya manusia yang kreatif, inovatif dan produktif diperlukan sistem pendidikan yang berkualitas agar tujuan tersebut dapat tercapai maka diperlukan dukungan dan perhatian dari berbagai pihak terutama dari pemerintah.

Sebagai pendidik kita dituntut harus mampu mendesain dan melakukan program pengalaman dengan tepat agar peserta didik mampu meningkatkana hasil belajar terutama pada mata pelajaran Matematika. Pada mata pelajaran Matematika tingkat sekolah dasar masih terdapat cara mengajar yang monoton dan kurangnya penggunaan media pada pembelajaran matematika, sehingga peserta didik kurang tertarik. Oleh sebab itu, maka diperlukan model pembelajaran yang menarik dan menyenangkan bagi peserta didik sehingga dapat meningkatkan hasil belajar peserta didik. Proses pembelajaran pada mata pelajaran Matematika masih bersifat satu arah (teacher centered), yaitu hanya menyampaikan penjelasan dari materi pelajaran dan peserta didik sebagai penerimanya yang pasif.

Salah satu alternatif model
pembelajaran yang dapat
dikembangkan untuk memenuhi
tuntutan tersebut adalah model
Explicit Instruction dan Course
Review Horay. Model pembelajaran
tentunya harus sesuai dengan variabel pembelajaran. Dengan demikian, guru profesional dituntut harus bisa merencankan, memilih dan menggunakan berbagai model pembelajaran yang sesuai dengan tujuan pembelajaran yang diinginkan dan ini adalah salah satu cara guru menciptakan pembelajaran yang menarik dan yang menyenangkan bagi peserta didik khususnya pada mata pelajaran Matematika. 
Walaupun metode Explicit Instruction dan Course Review Horay masih memiliki sejumlah kelemahan dalam penerapannya, tetapi model pembelajaran Explicit Instruction dan Course Review Horay memiliki keuntungan dan kelebihan. Selain itu juga ada dampak positif bagi peserta didik dalam menggunakan model Explicit Instruction dan Course Review Horay dalam proses pembelajaran yaitu, mampu memotivasi peserta didik dalam belajaran, adanya interaksi pada peserta didik lainnya sehingga semua peserta didik menjadi aktif, tidak hanya terpaku pada penjelasan guru.

Peneliti menggunakan media manipulatif dalam pembelajaran matematika SD. Guru membuat peserta didik lebih mudah memahami materi pembelajaran dan bisa membuat peserta didik menjadi lebih aktif berpartipasi dalam belajar. Media manipulatif merupakan segala benda yang dapat dilihat, disentuh, didenger, dirasakan dan manipulasikan. Benda manipulatif dapat diartikan sebagai alat untuk menerangkan atau mewujudkan konsep matematika, alat yang digunakan dapat berupa benda nyata

Berdasarkan hasil observasi dan wawancara yang dilakukan peneliti pada wali kelas dan peserta didik kelas VB SD Negeri 3 Langkai Palangkaraya maka peneliti menemukan masalah atau kendala yaitu kurangnya pemahaman peserta didik terhadap materi pembelajaran Matematika, hal ini di sebabkan pembelajaran kurang inovatif, sehingga mengakibatkan peserta didik sering menunjukan sikap belajar yang kurang baik. Hasil belajar peserta didik dalam mata pelajaran Matematika masih rendah. Dari kelas VB yang diteliti berjumlah 27 peserta didik, $46.43 \%$ mencapai kriteria ketuntasan belajaran dan $53.57 \%$ peserta didik belum mencapai kriteria belajar. Sedangkan kriteria nilai ketuntasan minimal (KKM) untuk mata pelajaran Matematika yaitu 65 .

Makmun (2014: 5) Belajar adalah suatu proses psikis yang berlangsung dalam interaksi antara subjek dengan lingkungannya dan menghasilkan perubahan-perubahan dalam pengetahuan, pemahaman, keterampilan, sikap dan kebiasaan yang bersifat relatif konstan/tetap baik memalui pengalaman, latihan maupun praktek. Perubahan itu bisa sesuatu yang baru atau hanya penyempurnaan terhadap hal-hal yang sudah dipelajari yang segara nampak dalam perilaku nyata atau yang masih tersembunyi.

Menurut Bloom (Suprijono, 2015: 6-7) mengatakan bahwa Hasil belajar mencakup kemampuan kognitif, afektif, dan psikomotor. Domain kognitif adalah knowledge (pengetahuan, ingatan), comprehension (pemahaman, menjelaskan, meringkas, contoh), application (menerapkan), analysis (menguraikan, menentukan hubungan), synthesis (mengorganisasikan, merencanakan, 
membentuk bangunan baru), dan evaluation (menilai). Domain afektif adalah receiving (sikap menerima), responding (memberikan respon), valuing (nilai). Organitation (organisasi), characterization (karakterisasi). Domain psikomotor meliputi initiatory, pre-routine, dan rountinized.

Fatimah (2009) Pembelajaran matematika adalah membentuk logika berpikir bukan sekedar pandai berhitung. Berhitung dapat dilakukan dengan alat bantu, seperti kalkulator dan komputer, namun menyelesaikan masalah perlu logika berfikir dan analisis. Einstein mengatakan "Pure mathematics is, in its way, the poetry of logical ideas". Matematika adalah puisi logika. Bangun ruang adalah bangun Matematika yang memiliki isi atau volume. Bangun ruang disebut juga bangun tiga dimensi karena memiliki ruang serta sisi-sisi yang membatasinya. Jumlah serta bentuk dari setiap sisi yang ada menjadi ciri khas tersendiri dari sebuah bangun ruang. Beberapa macam bangun ruang meliputi prisma tegak segitiga, limas segitiga, tabung, dan kerucut.

Menurut Suprijono (2015:65) Membelajaran ialah pola yang digunakan sebagai pedoman dalam merencanakan pembelajaran di kelas maupun tutorial. Model pembelajaran mengacu pada pendekatan yang akan digunakan, termasuk di dalamnya tujuan-tujuan pembelajaran, lingkungan pembelajaran, dan mengelola kelas. Model pembelajaran dapat didefinisikan sebagai kerangka konseptual yang melukiskan prosedur sistematis dalam mengorganisasikan pengalaman belajar untuk mencapai tujuan belajar. Model pembelajaran berfungsi pula sebagai pedoman bagi para perancang pembelajaran dan para guru dalam merencanakan aktivitas belajar mengajar.

$$
\text { Majid (2013: }
$$
menyatakan bahwa Pembelajaran langsung pada umumnya dirancang secara khusus untuk mengembangkan aktivitas belajar peserta didik yang berkaitan dengan aspek pengetahuan prosedural (pengetahuan tentang bagaimana melaksanakan sesuatu) dan pengetahuan deklaratif (pengetahuan tentang sesuatu yang dapat berupa fakta, konsep, prinsip, atau generalisasi) yang tersruktur dengan baik dan dapat dipelajari selangkah demi selangkah. Fokus utama dari pembelajaran ini adalah pelatihan-pelatihan yang dapat diterapkan dari keadaan nyata yang sederhana sampai yang lebih kompleks.

Menurut Shoimin (2014:54) Pembelajaran Course Review Horay merupakan salah satu pembelajara kooperatif, yaitu kegiatan belajar mengajar dengan cara mengelompokan peserta didik dengan memasukan kedalam kelompokkelompok kecil. Pembelajaran ini merupakan suatu pengujian terhadap pemahaman konsep peserta didik menggunakan kotak yang diisi dengan soal dan diberi nomor untuk menuliskan jawabannya. Peserta didik yang paling terdahulu 
mendapatkan tanda benar langsung berteriak horey atau yelyel lainnya. Melalui pembelajaran Course Review Horay diharapkan dapat melatih peserta didik dalam menyelesaikan masalah dengan pembetukan kelompok kecil.

Arends (2008: 110) Guru menerapkan dua strategi utama untuk memenuhi kebutuhan seluruh siswa menggunakan multiple models of instruction. Menggunakan multiple models berarti bahwa guru mengambil beberapa model mengajar dan memilih berbagai pendekatan yang berbeda tergantung tujuan belajarnya. Hal itu juga berarti bahwa mereka mampu menghubungkan dan menggunakan berbagai model yang berbeda secara tandem selama sebuah pelajaran atau sebuah unit kerja.

Langkah-langkah daripada penggabungan model Explicit Instruction dan Course Review Horay dalam kegiatan pembelajaran yaitu sebagai berikut:

1. Menyampaikan kompetensi/ tujuan pembelajaran dan mempersiapkan peserta didik

2. Memdemonstrasikan/menyampai kan materi.

3. Membimbing pelatihan kepada peserta didik

4. Memberikan kesempatan peserta didik untuk bertanya.

5. Untuk menguji kepahaman, peserta didik disuruh membuat kotak 9/6/25 sesuai dengan kebutuhan dan tiap kotak diisi angka sesuai dengan selera masing-masing peserta didik.

6. Guru membaca soal secara acak dan peserta didik menulis jawabannya di dalam kotak yang nomornya disebutkan guru dan langsung diskusikan. Kalo benar diisi tanda benar dan yang salah diisi tanda silang.

7. Peserta didik yang sudah mendapat tanda vertical atau horizontal atau diagonal harus berteriak horay atau yel-yel lainnya

8. Nilai peserta didik dihitung dari jawaban benar jumlah horay yang diperoleh.

9. Mengecek pemahaman peserta didik dan memberikan umpan balik

10. Memberikan kesempatan kesempatan kepada peserta didik untuk latihan lanjutan

11. Kesimpulan

12. Penutup

Menurut Ibrahim dkk (Kustiawan 2016:6) "media pembelajaran adalah segala sesuatu yang digunakan untuk menyalurkan pesan (bahan pembelajaran) sehingga dapat merangsang perhatian, minat dan perasaan peserta didik dalam kegiatan belajar untuk mencapai tujuan pembelajaran tertentu".

Arsyad

(2014:16)

"Transformasi suatu kejadian atau objek dimungkinkan karena media memiliki cirri manipulatif. Kejadian yang memakan waktu yang berharihari dapat disajikan kepada peserta didikdalam waktu dua atau tiga menit ...." 


\section{METODELOGI PENELITIAN}

Penelitian ini dilaksanakan dari bulan Maret 2018 sampai dengan bulan Mei 2018 di SDN 3 Langkai Palangkaraya yang terletak di Jl. Temanggung Raya, Kel. Langkai, Kec. Pahandut, Kota Palangkaraya, Prov. Kalimantan Tengah.

Penelitian Tindakan Kelas (PTK). Menurut Arikunto (2018:58) "Penelitian Tindakan Kelas adalah penilitian tindakan (action research) yang dilakukan dengan tujuan memperbaiki mutu praktik pembelajaran di kelasnya".

Peran peneliti dalam penelitian ini sangatlah penting karena peneliti mutlak diperlukan pada setiap kegiatan ditempat penelitian dikarenakan peneliti berperan sebagai perencana, pelaksana, pengamat, reflector, dan sebagai pelapor hasil penelitian.

Subjek penelitian adalah peserta didik kelas VB SDN-3 Langkai dengan jumlah keseluruhan peserta didik sebanyak 27 orang, terdiri dari 15 laki-laki dan 12 perempuan.

Rancangan penelitian ini menggunakan model Kemmis dan Mc Taggart (Paizaluddin \& Ermalinda, 2016:30), rangkaian kegiatan yang berurutan dan berkesinambungan yang dicirikan dengan adanya model kerja dilakukan peneliti dengan menggunakan siklus-siklus, setiap siklus terdiri dari empat tahapan yaitu: perencanaan tindakan, pelaksanaan tidakan, observasi, dan refleksi/ evaluasi, dan refleksi/ evaluasi. Teknik pengumpulan data dalam penelitian ini adalah observasi dan tes. Instrument penelitian menggunakan pre test dan post test.

Data yang dikumpulkan dalam setiap siklus akan dianalisis menggunakan metode Mixed Methods atau metode kombinasi antara kualitatif dan kuantitatif. Menurut Creswell (Emzir 2014:9\&27) menyatakan bahwa : Mengemukakan tiga pendekatan penelitian, yaitu pendekatan kuantitatif, pendekatan kualitatif, dan penekatan metode gabungan (imixed methods approach). Untuk memahami ketiga pendekatan tersebut menurut Creswell, penelitian perlu memperhatikan tiga elemen kerangka kerja yaitu, asumsi-asumsi filosofi tentang apa yang membentuk tuntutanpengetahuan (knowledge claims); dan prosedur umum penelitian yang disebut strategies of inquiry ; dan prosedur detail pengumpulan data, analisis, dan penulisan, yang disebut metode. Sedangkan prosedur kualitatif, kuantitatif dan metode gabungan: Metode penelitian kuantitatif ditentukan sebelumnya. Instrument berdasarkan pertanyaan data perinformasi, data sikap, data observasi dan data sensues, analisis statistik. Metode kualitatif emerging methods, petanyaan terbuka, dan interview data observasi, data dokumen, dan audio visual analsis teks dan gambaran. Metode penelitian metode gabungan yaitu keduanya 
ditentukan emerging methods, kedanya pertanaan terbuka dan tertutup. Berbagai bentuk penggambaran datayang memungkinkan analisis statistic dan analisis teks.

\section{HASIL DAN PEMBASAHAN}

Data dari hasil penelitian ini berupa: 1) pengamatan aktivitas guru dan peserta didik 2) hasil belajar matematika dengan menggunakan model Explicit Instruction dan Course Review Horay

Gambar 1.

Grafik Aktivitas Belajar Guru Dan Peserta Didik

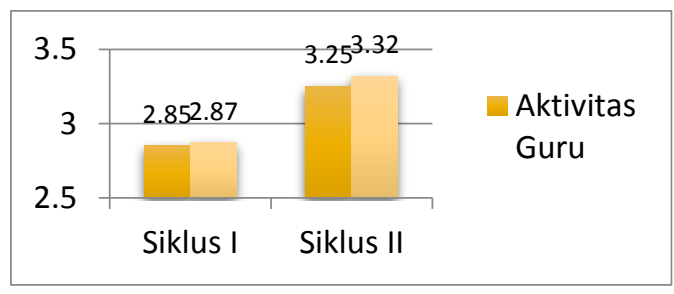

Aktivitas guru pada siklus I memperoleh nilai rata-rata 2.85 . sedangkan pada siklus II ada peningkatan yang lebih baik, dengan penilaian rata-rata dari pengamat yaitu 3.25. Dan aktivitas peserta didik pada siklus I nilai rata-ratanya 2.87 , pada siklus II meningkat menjadi 3.32. berdasarkan hasil tersebut dapat dilihat bahwa terjadi peningkatan aktivitas guru dan peserta didik dari siklus I dan siklus II.
Gambar 2

Hasil Belajar Matematika Peserta Didik Kelas VB

\begin{tabular}{|c|c|c|}
\hline \multirow{3}{*}{$\begin{array}{r}100 \\
50\end{array}$} & $9359 \%$ & \multirow{3}{*}{ Rata-rata } \\
\hline & $44 \quad 63$ & \\
\hline & $25 \%$ & \\
\hline & Pre Siklus Siklus & Ketuntasan \\
\hline & Test I & Klasikal \\
\hline
\end{tabular}

Berdasarkan tabel diagram di atas, pada hasil pre test peserta didik belum memuaskan karena hanya mendapatkan nilai rata-rata 44 dengan presentase ketuntasan hasil belajar 25\%. Pada siklus I peserta didik mendapatkan $51.85 \%$ namun masih belum mencapai nilai dari ketuntasal klasikal. Pada siklus II mengalami peningkatan sangat bagus dengan perolahan nilai rata-rata 79 dengan presentase ketuntasan secara klasikal mencapai $92.59 \%$.

\section{KESIMPULAN}

1. Aktivitas belajar peserta didik kelas V-B SDN 3 Langkai pada pembelajaran Matematika melalui model pembelajaran Explicit Instruction dan Course Riview Horay berbantu media manipulatif menjadi baik. Peserta didik menjadi lebih bersemangat dan aktif dilihat dari nilai rata-rata yang diberikan siklus I adalah 2.87 dengan kriteria kurang baik dan siklus II aktivitas peserta didik meningkat dengan nilai 3.32 dengan kriteria baik.

2. Ada peningkatan hasil belajar Matematika dengan menggunakan model Explicit Instruction dan 
Course Riview Horay berbantu media manipulative pada kelas $\mathrm{V}$ B SDN 3 Langkai Palangkaraya Tahun Pelajaran 2017/2018. Nilai rata-rata pada pre test 44 dengan ketuntasan klasikal 25\%, pada siklus I hasil bleajar peserta didik mengalami peningkatan yaitu memperoleh nilai rata-rata 63 dengan ketuntasan klasikal $51,85 \%$, dan pada siklus II hasil belajar peserta didik menjadi lebih meningkat yaitu memperoleh nilai rata-rata 79 dengan ketuntasan klasikal 92,59\%.

\section{DAFTAR PUSTAKA}

Abdul Majid. 2013. Perencanaan Pembelajaran. Bandung: Remaja Rosdakarya.

Makmun Khairani. 2014. Psikologi Belajar. Yogyakarta: Aswaja Pressindo.

Suprijono. 2015. Cooperative Learning Teori \& Aplikasi Paikem. Yogyakarta: Pustaka Pelajar.

Aris Shoimin. 2014. 68 Model Pembelajaran Inovatif dalam Kurikulum 2013. Yogyakarta: Ar-Ruzz Media.

Kustiawan. 2016. Pengembangan Belajar Anak Usia Dini. Malang: Gunung Samudra.

Arsyad. 2014. Media Pembelajaran. Jakarta: Rajawali Pers.

Richard Arends. 208. Learning to Teach. Penerjemah: Helly 